\title{
Intangible Assets and Internal Controls in Global Companies
}

\author{
Daniela M. Salvioni*
}

\begin{abstract}
The effectiveness of corporate governance processes on global markets entails the adoption of ramified internal control systems, and the adaptation of the variables that are significant to this end to respond to the evolution of surrounding conditions.

Analysis of the changes that have taken place in the main variables on which global companies concentrate their attention and their controls reveals, in particular, a growing need to evolve from the dominance of tangible components to a situation that takes intangible assets into due consideration. We refer to the corporate culture and the information system which represent both elements on which the effectiveness of governance processes is based and factors to be monitored with suitable internal control procedures.
\end{abstract}

Keywords: Corporate Governance; Internal Control; Intangible Assets; Global Competition

\section{Governance and Control on Global Markets}

Global markets impose the adoption of governance systems designed to promote management, control and communication processes, able to simplify a company's success in an increasingly complex economic context.

The gradual fall of space and time barriers to the circulation of information, goods and capital, is accompanied by new broad confrontation between more industrialised countries and emerging countries, and by an increase in the number of benchmark nations for the governance of the world economy (we only have to think how we have progressed from the G6 in 1975 to the G7, the G8 and now the G20, which represents $90 \%$ of world GDP and almost two thirds of the inhabitants of our planet).

Modern economic systems also reveal the spread of general strategies designed to regulate access to capital markets (for example, the Basel Accords on credit capital, the rules of access and the principles of self-discipline for the Stock market, etc.), the growing dynamism of the buying and selling markets and the increasingly

*Full Professor of Business Administration, University of Brescia (salvioni@eco.unibs.it)

Edited by: ISTEI - University of Milan-Bicocca

ISSN: 1593-0319

Salvioni Daniela M., Intangible Assets and Internal Controls in Global Companies, Symphonya. Emerging Issues in Management (symphonya.unimib.it), n. 2, 2010, pp. 39-51

http://dx.doi.org/10.4468/2010.2.4salvioni 
frequent emergence of competitive scenarios characterised by an excess of supply over the demand for goods.

Globalisation induces companies to dynamically review their choice of locations, also based on considerations of convenience deriving from cost differentials (manpower, electricity, tax holidays, etc.) and the development rate of markets. A company's ability to innovate its products and processes becomes increasingly important to maintain the conditions for success ${ }^{1}$, it is more urgent to develop specific competitive capabilities and the timing of assessment processes becomes progressively shorter.

Companies currently have to respond to important stakeholders, who are very articulate, well informed and able to make comparative convenience analysis. As a result, the corporate governance approach has to be improved, by focusing on the logics of a competitive approach in all interactive markets and on close links between economic, competitive and socio-environmental management variables.

In the new market context, the risk elements to which companies are exposed multiply, and the crucial factors that can influence management success are changing. In consideration of the interdependence between top management decisions and organisational behaviour, the effectiveness of governance demands the adoption of increasingly broad, comprehensive internal control systems - based on a culture that is shared and disseminated throughout the company, and on complex information systems - able to monitor and to immediately call attention to any changes in the factors that are crucial for the company's success.

Corporate governance presupposes a reference to varied objectives, whose goals are to exploit the entire network of internal and external relations, to optimise behaviour in respect of stakeholders' expectations, to exchange information and to adopt ethical conduct throughout.

The complexity of corporate relations is reflected, first of all, in a growing need for information, which is necessary to guarantee the optimisation of relations, resources, activities and results in a very dynamic context. Information is an asset that underpins the quality of corporate governance, whose suitability and immediacy is essential to take conscious decisions that can sustain competitive effectiveness, combat threats and exploit the opportunities offered by the global environment.

The assertion and sharing of values that are significant for responsible management and target sustainability are an important aspect of the coordination and uniformity of behaviour, a decisive resource for the company's success. In particular, the internalisation of values and principles that are common to top management and to the organisation facilitates the correct implementation of governance processes, promotes the adoption of an effective and efficient managerial approach, and favours both the institution of positive relations between the company and its stakeholders and risk containment ${ }^{2}$.

Maintaining a company's competitive vitality in an increasingly open and dynamic environment, underlines the importance of:

- an enhanced overall view of governance, focused on the harmonisation between top management and operating decisions, and between corporate governance and internal control systems that sustain the effective optimisation of company results; 
- the development of control systems that are fully compliant with evolving operations and make it possible to monitor risks related to the various significant dimensions;

- adjustments to the variables to be monitored, focusing increasingly on the intangible assets that are crucial for the company's success.

The significant dimensions by which companies are assessed have changed constantly over the years, the control procedures that guarantee an effective development of activities have multiplied, and communication - both internal and external - has become more important.

On global markets, the achievement of optimal conditions of corporate effectiveness presupposes, above all, emphasis on the relations between corporate governance and internal control systems, the dissemination at all organisational levels of shared values and attitudes based on fairness, correctness and transparency, the drafting of suitable information and constant verification of their suitability in the evolving conditions. The corporate culture and information system are therefore intangible resources that are essential for the effectiveness of the governance process but also factors to be monitored constantly as part of the internal control processes.

\section{Internal Control Systems and Critical Managerial Factors}

Recovering corporate competitiveness, particularly for companies operating in countries where industrialisation goes back a long way, with salaries and overheads that are decidedly high compared to emerging economies, demands internal control systems that can provide an essential support to conscious governance ${ }^{3}$.

An internal control system implies changes to information and management processes, and is applied at an organisational level, reflecting policies and structures defined by the corporate governance organs. It comprises a range of mechanisms that support the correct implementation of governance, and envisages several operating levels, organs and activities (Table 1).

Company management defines internal control policies that are consistent with company requirements, with existing legal constraints and with the complex internal and external situation, in order to disseminate accountability in all managerial behaviour.

The internal control system envisages the creation of specific dedicated positions (head of internal control, internal auditor, controller, compliance officer and watchdog, etc.), but also the involvement of operational management and of the entire organisation which, by its own behaviour, determines when and how concrete results are achieved.

The goals of the internal control processes, which are clearly interrelated, are primarily: to assess the validity of the procedures adopted, the transparency of behaviour and the consistency between accountability and operating processes (internal auditing); to manage corporate risks (risk management) and compliance with standards, regulations, procedures and internal codes of practice (compliance checks and, in Italy, controls required by Leg. Decree $231 / 2001)^{4}$; to guide the organisation to pursue results able to achieve established strategic targets in a 
coordinated manner, responsibly meeting stakeholders' legitimate expectations (management control).

All internal control activities aim to assure constant achievement of lasting conditions of corporate success, through the effective management and monitoring of particularly crucial elements.

Table 1: The Corporate Internal Control System

\begin{tabular}{|c|c|c|}
\hline Context & Organism & Internal Control Activities \\
\hline \multirow{2}{*}{$\begin{array}{l}\text { Corporate } \\
\text { Governance }\end{array}$} & B.o.D. and I.C. Committee & Planning/approval Coordination and evaluation \\
\hline & $\begin{array}{l}\text { Two-tier systems: control organ (Supervisory } \\
\text { Board - Board of Auditors) }\end{array}$ & Evaluation \\
\hline \multirow[t]{2}{*}{$1^{\text {st }}$ level } & $\begin{array}{l}\text { Head of Internal Control and Internal } \\
\text { Auditing }\end{array}$ & $\begin{array}{l}\text { Review/evaluation of the internal control } \\
\text { system, assurance, consultancy }\end{array}$ \\
\hline & $\begin{array}{l}\text { Watchdog organism and Compliance } \\
\text { Officer }\end{array}$ & $\begin{array}{l}\text { Respect of standards and regulations } \\
\text { Crime prevention }\end{array}$ \\
\hline \multirow[t]{2}{*}{$2^{\text {nd }}$ level } & Controller & $\begin{array}{l}\text { Orientation and coordination of organisational } \\
\text { behaviour. } \\
\text { Verification of consistency between objectives and } \\
\text { results }\end{array}$ \\
\hline & Risk manager & Operational risk management \\
\hline $3^{\text {rd }}$ level & Operational management and organisation & $\begin{array}{l}\text { Operational support to first and second level } \\
\text { organs with respect to coordinated units }\end{array}$ \\
\hline
\end{tabular}

A company's competitive, economic and social success derives from the interaction of a number of closely related factors which can play a crucial role, depending on the relevant environmental context, the strategic decisions taken, the structural set-up, the available tangible and intangible resources and the related trends and changes.

Critical factors of success tend to define a company's level of risk, because they are often associated with variables that express the threats and opportunities that distinguish its operations. From these factors derive the main qualitative and quantitative factors that sum up the level of operating effectiveness and efficiency, in other words the essential elements to direct and coordinate behaviour and to verify the consistency between objectives and results.

Respect of standards and regulations and crime prevention are all implemented with reference to the company's competitive, economic and social situation, and they therefore influence and are influenced by the critical factors.

Evaluation of their validity and efficiency, and the promotion of improvements to the internal controls, verification of the consistency between short and long-term objectives, and support to management to improve the effectiveness of checks, are prime expressions of the capacity to monitor risk related to critical factors.

Management of critical factors makes it simpler to achieve a suitable dominant position on the marketplace where the company operates, and consensus surrounding the proposals put forward regarding essential conditions of economic equilibrium and administrative and social-environmental accountability. The critical factors therefore represent variables that are:

- essential to orient organisational behaviour (management control);

- $\quad$ to be monitored in the context of the risk management system (ERM); 
- the basis for evaluation by the system of internal control, assurance and consultancy, to implement governance processes that are constantly consistent with the company's needs (internal auditing);

- correlated to the respect of standards, to the definition of possible crimes connected to activities and to related prevention (verification of compliance and supervision).

The effectiveness of the internal control system is therefore strongly influenced by a correct perception of the essential role of the critical factors. These are elements associated to external and internal factors, which derive from and influence corporate governance strategies and related processes to govern operating activities.

All the critical factors change dynamically, and are influenced to different degrees by changes to the relevant economic and social context, the competitive dimension and the management of each company. The sweeping change generated by the spread of economic globalisation is therefore reflected on the factors that are crucial for the success of the various companies and, through these, on the characteristics of the internal control processes adopted.

\section{Evolution of Critical Factors and Intangible Assets}

Globalisation and the changes that have taken place in economic systems in recent years have determined profound changes in the role of the stakeholders, on one hand, emphasising the close link between economic, social and environmental responsibility, and highlighting the importance of transparency and communication, and, on the other, a gradual transformation of the critical success factors, and/or their related importance, with sweeping implications in terms of the effectiveness of control systems.

In particular, since the end of the last century, the conditions that are essential for a company's success have undergone several changes, ascribable primarily to:

1. the growing importance of the role of knowledge in improving the capacity to adapt dynamically to changes in the environment, and in creating virtuous circles of resources, assets, results and consensus;

2. the importance of a positive competitive approach to the market, based on the enhancement of existing differentials and elements that innovate and qualify the company supply chain;

3. the pressing need to assert values, attitudes and interpretations disseminated throughout the organisation and dominating relations with company stakeholders.

Prevailing critical success factors have therefore seen a significant change, with the gradual spread of the broad conditioning that derives from specific intangible components which are important to establish conditions of competitive, economic and social effectiveness.

Intangible corporate assets make up a vast, heterogeneous universe of variables, often linked to exchange operations, and at other times deriving from processes of internal accumulation. What is more, these resources can be represented directly in 
a company's quantitative results, whereas in other cases it is difficult to insert them directly in economic measurements.

Among intangible assets, the corporate culture and information system have emerged increasingly as dominant critical success factors, because of their essential significance for the effectiveness of the governance.

The corporate culture and information system share some specific connotations, such as:

- being founded on knowledge and a process of accumulation in time ${ }^{5}$;

- the purely internal creation of their value, which derives from governance decisions designed to obtain competitive advantages;

- growing dynamism, even in relation to ever more frequent changes to the corporate structure;

- high volatility, which imposes constant checks, based on a selection of significant indicators of effectiveness;

- the impossibility of negotiation (acquisition/sale) separate from the company, except in particular situations;

- strong mutual influence and interdependence to create stable elements of competitive advantage;

- dependence of the related development on the chosen interaction with the various stakeholders;

- the impossibility of direct representation in economic reports, although these factors can often significantly influence the creation of stable conditions of income formation;

- a significant impact on a wide range of other intangible management elements - definable as secondary or derived - such as competitive positioning, the effectiveness of product and process development, the perceived quality of products/services, the suitability of internal control systems, the consonance of the behaviour and motivation of personnel, the quality of external relations, and so on.

The corporate culture and information system therefore constitute resources with a protracted economic utility, with the potential to grow on the basis of processes to constantly refine specific knowledge.

The culture and information system are mutually conditioned and gradually becomes more important for the achievement of effective processes of corporate governance and internal control. The system of internal control is actually influenced in the development of its own processes by the existence of an ethically correct culture, founded on strong values that are shared by the top management and the organisation, and by the quality of the information and communications system developed. As the same time, the internal control has to constantly monitor the value of the information system and corporate culture, identifying significant parameters that are the objective of measurement and evaluation, verifying its consistency with expectations and managerial requirements, underlining the need for improvements in relation to the weaknesses found. 


\section{The Corporate Culture in Internal Control Processes}

The corporate culture is the sum of the basic assumptions, values, attitudes and interpretations that permeate a given operating unit. The culture is born with the company and is gradually conditioned by a large number of internal and external factors, with ever broader spheres of influence, even in relation to the collapse of barriers to the transfer of resources and information, and the assertion of a converging concept of corporate accountability.

External variables (political, legal, social, economic, etc.) and positioning choices in the global economic environment influence the corporate culture and determine the need for coordination in the context of governance processes.

The conditions for success, the correspondence between an individual's values and those of the group in which he works, the capacity to spread values that dominate the entire organisation and to create motivating processes of learning and growth, all facilitate cohesion and the coordination of management processes.

Culture affects all corporate behaviour, determining the conditions of consonance and internal sharing, the potential for the image to assert itself, and the pursuit of consensus and managerial effectiveness. The existence of a strong culture, shared by top management and the organisation and permeating the entire network of corporate relations, is therefore a critical element for interaction with society and the optimisation of economic and competitive performance.

Internal controls aim to transfer corporate responsibilities in the operating processes, and to optimise the potential for success and durability compared to different and changing internal and external phenomena. As a result, the planning of control systems cannot overlook: an analysis of the existing culture, in terms both of general values and of specific values related to individual activities; an evaluation of the capacity of the control system to transfuse the conditions of corporate accountability throughout the organisation and to contribute to the spread of consistent values; verification of the optimisation the of cultural growth processes triggered by the company and the related constant consistency with the guidelines expressed by top management ${ }^{6}$.

The failure to transfer the values of accountability to the various managerial tasks can jeopardise the correct implementation of management decisions, to the detriment of the general corporate well-being. In this respect, global companies have highlighted the advisability of adopting ethical codes and behaviour that clearly outline the principles, values and responsibilities that the organisation must share, take on board and respect.

In more complex organisations that are exposed to globalisation, effective management of differences may also be sustained by the adoption of a plan to construct an ethical corporate culture, possibly supported by the appointment of an Ethics Officer (EO) and/or the creation of an Ethics Committee (EC).

Ethical, responsible codes of behaviour address all those who play a leading role in the exercise of its corporate responsibility: directors, executives, employees at all levels, but often also co-makers, external collaborators, suppliers and consultants. They are therefore a tool designed to spread the various principles and standards of behaviour, which can generate consensus, clarity and coordination between top management and the organisation. 
$\square$ The Ethics Code of Eni S.p.A. focuses both on the general principles of respect of the law, transparency, honesty, fairness and good faith, and on the goals of sustainable development, including the company's responsibility in relation to the territories in which it operates, the protection of third generation rights and the defence and promotion of human rights.

The general principles vary for the various types of stakeholder. In particular they focus on the following:

- relations with shareholders and the market: Eni's commitment to the creation of value for shareholders must be pursued following the principles of fairness in relation to the market. Reference is made to the main rules of corporate governance, the principles to follow in terms of corporate information and media relations, based on transparency and fairness, but also timeliness and precision;

- relations with institutions and local communities: it becomes compulsory to cooperate actively with public institutions, with a commitment to the development of local communities, even through information and consensus about issues of particular interest, support to non-profit organisations.

- relations with customers and consumers: the Code underlines the right not to receive products that are harmful to the health, but to receive comprehensive information about the products offered.

Moreover, particular attention is focused on relations with Eni personnel. The development and safeguarding of individuals is emphasised, respecting diversity, so that the workplace increasingly becomes an environment of mutual respect and collaboration. It also addresses the issues of company security and knowledge management.

All the rules of behaviour are guaranteed by suitable application tools, like the internal control system and the duty to avoid and to report conflicts of interest, to protect the health and safety of the individual, the environment and public safety and to promote research and innovation, safeguarding intellectual property.

Where the controls are concerned, the role of guarantor of the ethics code is entrusted to the Compliance and Watchdog organism, in order to create synergies and boost efficiency between the different forms of control.

The Code also envisages the creation of an Ethics Code Promotion Team to encourage its spread inside and outside Eni, recognising that if this tool is to be vital and functional, it must be understood and taken on board by all concerned.

However, there is a risk that the codes will generate limited effects - or phenomena of discontinuous application - without consistent control procedures and real collaboration between the organs responsible for spreading the ethics culture (EO and EC) and the internal control organs. The former promote ethically accountable behaviour and implementing initiatives to increase the awareness and importance of ethics in all players who are significant at an operating level. The latter are responsible for verifying from the inside: that the structures and relations 
promoting managerial behaviour are compatible with ethical conduct; that procedures maintain an optimal structure in time; that behaviour complies with standards and recommendations; that decisions are taken correctly and that behaviour is consistently oriented to objectives; that there is consistency between objectives and results, and compatibility with responsible management designed to minimise risks; any responsibility for the consequences of actions that do not meet the necessary requirements; that internal communications are transparent and that the procedures to spread operating accountability in the company are correct.

What is more, because of the importance of internal control systems for the company's efficiency, the principles for the spread of the control culture are often emphasised in corporate ethics codes as well as in models of organisation and control.

$\square$ The Code of Business Conduct of The Coca Cola Company states: 'Integrity is fundamental to The Coca-Cola Company.

Along with our other values of leadership, passion, accountability, collaboration, diversity and quality, it is a pillar of our Manifesto for Growth.

Integrity means doing what is right. By acting with integrity, we reflect positively on the image and reputation of the Company and its brands in the over 200 countries where we operate.

We all want to do what is right, for ourselves and for The Coca-Cola Company. The Code of Business Conduct will help guide us. The Code defines how employees should conduct themselves as representatives of The Coca-Cola Company. The Code addresses our responsibilities to the Company, to each other, and to customers, suppliers, consumers and governments.

We all must follow the law, act with integrity and honesty in all matters, and be accountable for our actions.'

In the paragraph about the tools for the application of the Ethics Code, the Eni S.p.A. model of internal control states: 'Eni promotes the dissemination, at every level of its organization, of policies and procedures characterised by awareness of the existence of controls and by an informed and voluntary control oriented mentality; consequently, Eni's management in the first place and all Eni's People in any case shall contribute to and participate in Eni's system of internal control and, with passive attitude, involve its collaborators in this respect'.

The parameters that control the corporate culture entail joint consideration of ethical values and business values, according to a two-tier development: the first based on elements such as the quality of relations between organisations, the degree of accountability, the transparency of relations and communications, the capacity to find creative solutions, the growth of professional skills, the difficulties of coordination, sharing and involvement, consistency between resources and results, respect of other people and trust, honesty, and openness to innovation; the second based on quantifiable elements such as the frequency with which deviances between objectives and results are seen, the speed of the internal transfer of important information and the notification of risk factors, the number of requests 
for training programmes, productivity indices, the frequency of measures designed to improve the respect of codes of behaviour and/or of corporate ethics codes, and so on.

\section{The Information System in Internal Control Processes}

The information system is significantly influenced by factors of internal and external dynamism, by the need for knowledge imposed by governance and by the dominant culture in the company. The system of people, equipment and procedures that collect, classify, process and transfer information which is pertinent and important for the governance of the company is the result of decisions taken at management and organisation level.

The quality and immediacy of information and the way the system adapts to the changing need for knowledge, influence the following in particular:

- the correct perception of the external availability of resources and their appeal;

- appreciation of stakeholders' expectations;

- the competitive approach to the market and the perception of factors of constraint, opportunities and threats;

- knowledge of the variables that influence organisational behaviour, of disseminated values, of the permeability of the social system and the potential for sharing goals;

- the correct definition of the critical success factors and the choice of the related target parameters;

- the effective comparison between parametric quantities and actual results and the interpretation of any divergence;

- the evaluation of the correctness of procedures and the transparency of information transmitted internally and externally.

All the decisions and corporate action taken presuppose information. It is essential to constantly upgrade the information system for the effectiveness of corporate governance, for internal control activities and to create virtuous circles of resources/activities/results.

Internal control processes in particular base their validity on the quality of the corporate information system, which represents a structural basis for each specific control activity, but also a common reference from which they receive and to which they can provide input. What is more, the role of critical resource of the corporate information system emphasises the need to verify its value in relation to contextual conditions, in order to constantly optimise its contribution to results.

$\square$ The list of objectives contained in the Policy Guidelines of the Tod's S.p.A. internal control system states: '...guaranteeing reliable information systems and suitable reporting processes at the various levels to which control functions are allocated; guaranteeing that any anomalies found are immediately reported to the appropriate company levels; allowing the registration of every operating event and, in particular, of every operation with a suitable degree of detail, guaranteeing its correct attribution in terms of timing.' Moreover, the duties attributed to the Manager responsible for internal controls include the definition of the information 
flows designed to guarantee complete knowledge and governability of corporate events; while those responsible for internal controls are responsible for verifying the reliability of information flows, including the automatic data processing systems and the administrative-accounting measurement systems.

The implementation of broader and more targeted internal control processes should help to refine the company's information system: both as an effect of a definition of the specific requirements of each process and their harmonisation to avoid useless and costly process duplications, and as a consequence of the development of suitable activities to verify the quality of the information produced and disseminated by the company in relation to the potential to create the conditions for competitive, economic and social success.

A carefully monitored information system should have characteristics of effectiveness to meet the specific objectives it sets itself, such as: speed, reliability, clarity, comprehensiveness, fairness, verifiability and transparency.

The control parameters of the company's information system should therefore be structured to verify that it is always the optimum in a global context. In this regard, at one level, indices such as compliance with the demand for knowledge, the capacity to perceive customers' changing expectations, and the reporting of risks and opportunities, become more significant. At a second level, it is possible to employ indices such as the many demands for integration, the reliability of the information, the frequency of inconsistencies between the need and the availability of information, the time necessary to adapt to change, the time to obtain useful elaborations for decision-making and appraisal purposes, the frequency of consultancy of the information produced, and so on.

\section{Intangible Assets and Performance}

In successful companies, the significant characteristics of the internal control systems have gradually adapted to changes in the global competitive context.

The emergence of new competitors and of significant differentials in growth rates between mature markets and emerging markets, has undoubtedly emphasised the importance of corporate governance designed to exploit market opportunities (market-driven management), supported by effective internal control systems. For example, internal control is called on to constantly monitor factors that are critical for the optimisation of performance and the rapid reporting of significant evolutionary phenomena and related risk factors to top management.

In today's competitive context, the key drivers of success have expanded, according to processes designed to emphasise the importance of some corporate intangible assets for the optimisation of overall performance. In this regard, in global companies, the culture and information system have acquired a primary governance role, because they are essential conditions of success.

Culture and information systems are preconditions for effective governance, factors to be constantly verified with respect to the evolution of a company's network of relations. 
The optimisation of performance therefore presupposes the analysis of the essential characteristics of the culture and information system in terms of strategic development guidelines, the formalisation of related principles in governance documents, constant internal control by an evaluation of its effectiveness in the context of compliance analysis, coordination processes and behaviour orientation, operational risk management, and assurance.

The growing importance of the founding values of an organisation and of related cultural connotations, of internal and external systems to collect, process and transfer information, entails several difficulties regarding the way the related control actions should be performed. For these corporate intangibles it becomes necessary to identify indicators that allow them to be monitored, adopting processes that translate qualitative performance elements into consistent quantitative indicators supporting the optimisation of decisions and actions.

The evolution of competitive conditions has therefore induced not only the expansion of internal control processes, but also a significant effort to adapt to the variables to monitor. Traditional economic measures (income and financial) have gradually been replaced by an integrated system of measurements designed to perfect quantitative-monetary analyses and to bring economic results into line with assessments of stakeholder satisfaction (outcome), of analysis of the competition and markets, internal productivity, learning, and the cultural growth of the organisation.

Competitive, economic and socio-environmental performances find primary determinants in the correct competitive approach to the market that permeates governance strategies and the organisational performance that they generate.

In global companies, the optimisation of the competitive orientation and organisational performance is increasingly conditioned by the existence of a pervasive culture, founded on shared values and able to generate coordination, involvement, uniformity of behaviour and a sense of belonging.

Moreover, competitive effectiveness, the ability to forge alliances with stakeholders, correct risk management, and the quality and speed of decision-making, are clearly influenced by the ready availability of all significant internal and external information, as well as the capacity of the information and communication system to contribute to the organisation's cultural growth according to principles of accountability, collaboration and transparency.

\section{Bibliography}

Aglietta M., Corporate Governance and the Long-Run Investor, International Review of Applied Economics, vol. 22, n. 4, 2008. http://dx.doi.org/10.1080/02692170802137497

Adobor H., Exploring the Role Performance of Corporate Ethics Officers, Journal of Business Ethics, vol. 69, n. 1, 2006.

http://dx.doi.org/10.1007/s10551-006-9068-7

Clarke T., International Corporate Governance. A Comparative Approach, Routledge, London, 2007.

Djelic M.L., Sahlin-Andersson K., Transnational Governance. Institutional Dynamics of Regulation, Cambridge University Press, Cambridge, 2006.

Finkelstein S., Hambrick D., Cannella A.A. Jr., Strategic Leadership, Oxford University Press, New York, 2009. 
Goering G.E., Corporate Social Responsibility, Durable-Goods and Firm Profitability, Managerial and Decision Economics, John Wiley \& Sons Ltd., vol. 31, 2010.

http://dx.doi.org/10.1002/mde.1508

Huse M., Board, Governance and Value Creation, Cambridge University Press, United Kingdom, 2007.

Nonaka I., Takeuchi H., The Knowledge-Creating Company, Oxford University Press, New York, 1995.

Salvioni D.M., Corporate Governance and Global Responsibility, Symphonya. Emerging Issues in Management (symphonya.unimib.it), n. 1, 2003. http://dx.doi.org/10.4468/2003.1.05salvioni

Salvioni D.M., Market-Driven Management and Corporate Governance, Symphonya. Emerging Issues in Management (symphonya.unimib.it), n. 2, 2008. http://dx.doi.org/10.4468/2008.2.02salvioni

Salvioni D.M., Bosetti L., Corporate Responsibility, Ethics and Management Control. Some Evidence from Italian Public Utilities, Frenkel D.A., Gerner-Beuerle C. (eds.), Challenges of the Law in a Permeable World, Atiner, Athens, 2009.

Van den Berghe L., Corporate Governance in a Globalising World: Convergence or Divergence?, Kluwer Academic Publishers, USA, 2002.

\section{Notes}

${ }^{1}$ In advanced economies, in particular, technological innovation is often an essential factor to maintain the competitiveness of companies, due to the lower personnel costs and overheads typical of the operating units in emerging countries, and to the expanding phenomena of over-supply. Innovation rapidly makes the goods and services produced with the previous technology obsolete; on the other hand, it boosts the competitiveness of countries with higher salaries and overheads (advanced economies with higher living standards), often generating a surplus of resources to be reinvested in innovation to maintain the conditions of competitive success.

${ }^{2}$ Salvioni D.M., Corporate Governance and Global Responsibility, Symphonya. Emerging Issues in Management (symphonya.unimib.it), n. 1, 2003.

${ }^{3}$ In 1992 the COSO (Committee of Sponsoring Organizations of the Treadway Commission) gave the following definition: 'Internal control is a process, effected by an entity's board of directors, management and other personnel, designed to provide 'reasonable assurance' regarding the achievement of objectives in the following categories:

- $\quad$ Effectiveness and efficiency of operations

- $\quad$ Reliability of financial reporting

- Compliance with applicable laws and regulations.'

The aforesaid document, revised in 2004, has significantly influenced the subsequent development of legislative standards and codes of self-discipline for internal control systems at an international level.

${ }^{4}$ In Italy, Leg. Decree 231/2001, and subsequent amendments, envisages the adoption of a Model of Organisation, Management and Control, i.e. an organic system of principles, rules, (internal) instructions, schemes and organisational procedures with relative duties and responsibilities, instrumental to achieving and correctly managing a system to control and monitor 'risk' activities, in order to prevent the crimes referred to by the Decree being committed, or even attempted. To this end, the Decree envisages the creation of a special Watchdog with specific internal control functions.

5 Nonaka I., Takeuchi H., The Knowledge-Creating Company, Oxford University Press, New York, 1995

${ }^{6}$ Salvioni D.M., Bosetti L., Corporate Responsibility, Ethics and Management Control. Some Evidence from Italian Public Utilities, Frenkel D.A., Gerner-Beuerle C. (eds.), Challenges of the Law in a Permeable World, Atiner, Athens, 2009. 